\title{
A biotech-systematic approach to select fungi for bioconversion of winery biomass wastes to nutrient-rich feed
}

\author{
Bo Jin ${ }^{a, *}$, Florian Zepf ${ }^{a}$, Zhihui Bai ${ }^{b}$, Baoyu Gaoc, Nanwen Zhu ${ }^{d}$ \\ a School of Chemical Engineering, The University of Adelaide, Adelaide, SA 5095, Australia \\ $\mathrm{b}$ Department of Environmental Biotechnology, Research Center for Eco-Environmental Sciences, Beijing 100085, \\ China \\ c School of Environmental Science and Engineering, Shandong University, Jinan, China \\ d School of Environmental Science and Engineering, Shanghai Jiao Tong University, 800 Dongchuan Road, \\ Shanghai 200240, China
}

\section{A R T I C L E I N F O}

\section{Article history:}

Received 15 September 2015

Received in revised form 30 May

2016

Accepted 27 June 2016

Available online 2 July 2016

\section{Keywords:}

Bioconversion

Digestibility

Fungi

Protein enrichment

Winery biomass waste

Solid state fermentation

\begin{abstract}
A B S T R A C T
Grape marc and lees are main waste biomass in wine industry, which contain substantial amount of carbohydrates and nutrients, but currently deliver considerable carbon emission through landfill in Australia. This study was aimed to develop a biotechnological systematic approach to select suitable fungi for bioconversion of the winery biomass wastes into animal feed. The biotech-systematic approach was developed through assessment of nutrient/carbon source accessibility of the fungi, understanding of their metabolic reactions in solid state fermentation, and nutritive value of the fungi-fermented grape marc. From 13 Aspergillus, Rhizopus, and Trichoderma fungal species, A. oryzae DAR 3699, A. oryzae RIB40 and T. reesei RUT C30 were determined as the best fungi due to their promising biochemical capabilities to enhance protein contents and in vitro digestibility of grape marc in mono- and co-cultivations. The mono-fungous-cultured SSF process used these selected fungi is able to convert grape marc to nutrient-rich feed by increasing the protein contents from $\sim 5 \%$ to $26 \%$ and the digestibility from $\sim 25 \%$ to over $50 \%$. R. oligosporus 2710 with R. oryzae 6201 or T. viride 15719 showed promising protein enrichment to $18-23 \%$ and digestibility improvement by $\sim 50 \%$ in their co-cultivations. This preliminary bioengineering strategy will be useful for selecting microorganisms for the bioconversion of organic wastes to high valuable products. This "green cycle" bioprocess will be useful to promote the old-fashioned waste treatment technologies for the cleaner production in food processing industries.

(c) 2016 Institution of Chemical Engineers. Published by Elsevier B.V. All rights reserved.
\end{abstract}

\section{Introduction}

The wine industry is a growing industry in Australia. The Australian wine industries produce approximately 1.8 million tons/annum of grapes for wine production (Australian Bureau of Statistics, FAO), while generating about 450,000 tons of grape marc residues, which are treated as wastes by landfill.
The grape marc and wine lees contain substantial carbohydrates and nutrients, which are biodegradable and can be good substrates for biological production via solid state fermentation (SSF). SSF process provides an environment to support growth of microorganisms on solid substrates (Gelinas and Barrete, 2007). The SSF is a cost-effective process for the bioconversion of organic wastes to viable products. Most of

\footnotetext{
* Corresponding author. Tel.: +618 83137056.

E-mail address: bo.jin@adelaide.edu.au (B. Jin).
}

http://dx.doi.org/10.1016/j.psep.2016.06.034

0957-5820/@ 2016 Institution of Chemical Engineers. Published by Elsevier B.V. All rights reserved. 
reported studies on winery waste materials such grape marc focused on conventional technologies, such as biodegradation and composting and landfill processes (Sanchez et al., 2002; Vendruscolo et al., 2008). There are a few of recent studies which were conducted to use fungi for degrading hemicellulose biomass from winery (Karpe et al., 2015a, 2015b). There is a need to develop a technology for conversion of winery wastes to value-added products, leading to sustainable waste management strategy.

Fungi are often used in food industries as the sources of biomass and or by-products (Sankaran et al., 2010). Fungi can produce a wide range of chemicals and enzymes, and are more effective than bacteria in metabolizing complex carbohydrates such as starch and molasses (Hu et al., 2011; Jin et al., 1999a, 2002). The fungal biomass can be used as a source of animal feed (Jin et al., 2000, 2001; Zhang et al., 2008). Fungi are able to penetrate solid substrates for producing fungal biomass with high yields. Bioconversion of organic waste materials, such as the grape marc and wine lees, to value-added products offers an opportunity for the reuse of abundant waste materials from agro-industrial processes. Bioconversion has shown to be a promising process to improve the nutrition content and digestibility of the organic wastes, making them as protein-rich animal feedstock (Vendruscolo et al., 2008). This is an eco-friendly biotechnological approach for the sustainable development of wine industry.

This study was aimed to develop a biotech-systematic approach to select suitable fungi capable to convert winery wastes to protein-rich feed via SSF process. The study focused on improving protein contents and digestibility of the grape marc. The selection processes were carried out in a laboratory scale SSF system using white grape marc and red grape marc as carbon sources, and wine lees as nutrient source. The proposed biotech-systematic approach was developed through preliminary assessment of the nutritive components and safety for human and animal consumption of the fungal biomass, and evaluation of their metabolic capability to improve protein contents, digestibility, and sugar accumulation and consumption. A preliminary bio-systematic strategy will be developed to assess SSF performance of the tested fungal strains in mono- and co-cultivations using the grape marc, as well as nutrient sources. This biotech-systematic approach will be useful for selection of suitable microbial candidates for further investigations for optimization of fermentation conditions for protein enrichment of grape marc residuals using SSF processes.

\section{Material and methods}

\subsection{Microorganisms}

\subsubsection{Fungus species and strains}

Thirteen fungal strains of Aspergillus sp., Rhizopus sp. and Trichoderma sp. as listed in Table 1 were tested in this study. All fungal strains are considered as GRFS [Generally Recognized as Food Safe] by the US Food and Drug Administration (Sankaran et al., 2010). It is well known that Aspergillus sp. and Rhizopus sp. are starch consumers, while Trichoderma sp. are cellulase and hemicellulase producers (Zhang et al., 2008; Hu et al., 2011; Jin et al., 1999b, 2001, 2002). These fungal species, therefore, might be suitable candidates for protein enrichment of grape marc via a SSF process (Ghorai et al., 2009; Gummadi and Panda, 2003; Petre et al., 1999). The seed cultures were grown

\section{Table 1 - Fungus species employed in this study.}

\begin{tabular}{|c|c|c|c|}
\hline Species & Strain & Abbreviation & Source \\
\hline Aspergillus oryzae & DAR 3699 & AO 3699 & BCRI \\
\hline Aspergillus oryzae & RIB 40 & AO 40 & BCRI \\
\hline Aspergillus oryzae & 3863 & AO 3863 & BCRI \\
\hline Rhizopus arrhizus & 36017 & RA 36017 & BCRI \\
\hline Rhizopus oligosporus & 2710 & RO 2710 & BCRI \\
\hline Rhizopus oryzae & 1501 & RO 1501 & UALD \\
\hline Rhizopus oryzae & 2062 & RO 2062 & UQLD \\
\hline Rhizopus oryzae & 6201 & RO 6201 & CSIRO \\
\hline Trichoderma viride & 1544 & TV 1544 & CSIRO \\
\hline Trichoderma viride & 15719 & TV15719 & CSIRO \\
\hline Trichoderma reesei & 3967 & TR 3967 & CSIRO \\
\hline Trichoderma reesei & QM6a & TR QM6a & UQLD \\
\hline Trichoderma reesei & RUT C30 & TR C30 & UQLD \\
\hline \multicolumn{4}{|c|}{$\begin{array}{l}\text { BCRI: Biological and Chemical Research Institute, Sydney, NSW, } \\
\text { Australia. } \\
\text { CSIRO: Division of Food Science \& Technology, CSIRO, Sydney, NSW, } \\
\text { Australia. } \\
\text { UQLD: Culture Collection, The University of Queensland, Brisbane, } \\
\text { QLD, Australia }\end{array}$} \\
\hline
\end{tabular}

on potato dextrose agar slants for 5 days at $30^{\circ} \mathrm{C}$, maintained in a refrigerator at $4{ }^{\circ} \mathrm{C}$, and re-cultivated bimonthly.

\subsubsection{Inoculum}

Inocula of the tested fungi were grown on potato dextrose agar slants at $30^{\circ} \mathrm{C}$ in an incubator for 5 days. The spores were harvested as suspension with a spatula and transferred to $10 \mathrm{~mL}$ of a $0.05 \%$ Tween 80 solution under aseptic conditions. The number of the fungal spores was counted with the Neubauer counting chamber under the microscope. $2.5 \mathrm{~mL}$ of the spore solution, in which the spore concentration was adjusted to approximate $1 \times 10^{7}$ spores $/ \mathrm{mL}$, was used as an inoculum for the SSF tests.

\subsection{Winery residues}

\subsubsection{Grape marc residue}

Red grape marc (RGM) was obtained from Richmond Grove Winery and white grape marc (WGM) was provided by Orlando Wines in South Australia. The RGM was collected from fermentation tanks for red wine production. The WGM was the grape residues after juice extraction. The RGM contained $\sim 5 \%$ residual sugar analyzed as glucose and $\sim 3 \%$ protein, and had a digestibility of $\sim 25 \%$. The WGM contained approximate $8 \%$ glucose, $5 \%$ fructose and $5 \%$ protein, and had 30\% digestibility. The grape marc was dried at $50{ }^{\circ} \mathrm{C}$ for $24 \mathrm{~h}$ until its water content was reached less than $3 \%$. The dried grape marc residues were then stored at $4{ }^{\circ} \mathrm{C}$ for further use. All results presented in this paper are referred to the dried grape marc.

\subsubsection{Wine lees}

Wine lees are a waste product from the wine fermentation and aging processes, which consist of dead yeast cells, grape seeds, pulp, stems, skins and tartrates. The wine lees were collected from Richmond Grove Winery and Orlando Wines in South Australia, and were stored in a freezer at $-18^{\circ} \mathrm{C}$ until further use.

\subsection{Nutrient supplementation}

Standard trace element solution was used as nutrient supplementation in the tests, and contained $(\mathrm{g} / \mathrm{L}) 0.02 \mathrm{KH}_{2} \mathrm{PO}_{4}$, 
$0.02\left(\mathrm{NH}_{4}\right)_{2} \mathrm{SO}_{4}, 0.003 \mathrm{MgSO}_{4} \cdot 7 \mathrm{H}_{2} \mathrm{O}, 0.005 \mathrm{CaCl}_{2}, 0.00005$ $\mathrm{FeSO}_{4} \cdot 7 \mathrm{H}_{2} \mathrm{O}, 0.0000156 \mathrm{MnSO}_{4} \cdot \mathrm{H}_{2} \mathrm{O}$ and $0.000014 \mathrm{ZnSO}_{4} \cdot 7 \mathrm{H}_{2} \mathrm{O}$. These chemicals were purchased from Sigma-Aldrich Co., USA.

\subsection{Cultivation conditions}

\subsubsection{Mono-cultivation}

Dried grape marc samples $(15 \pm 0.25 \mathrm{~g})$ were added into a $250 \mathrm{~mL}$ Erlenmeyer flask and were mixed with Milli-Q water and/or nutrient sources as required. The flasks were sterilized at $121^{\circ} \mathrm{C}$ for $15 \mathrm{~min}$ and inoculated with $2.5 \mathrm{~mL}$ spore suspension $\left(1 \times 10^{7}\right.$ spores $\left./ \mathrm{mL}\right)$ after being cooled down to room temperature. The water content of the inoculated gram marc was controlled at approximately $65 \%$ in this study. The water content in the grape marc samples was determined by drying the samples at $60^{\circ} \mathrm{C}$ under vacuum for $8 \mathrm{~h}$ to achieve constant mass. The contents of each flask were gently tapped for $30 \mathrm{~s}$ to $\mathrm{mix}$ the spore suspension in the grape marc and were incubated statically at $30^{\circ} \mathrm{C}$ for 5 days.

\subsubsection{Co-cultivation}

The co-cultivation was carried out by inoculation of two different species and/or strains in the same SSF test, in which each strain was added with $1.2 \mathrm{~mL}$ of the prepared spore suspen$\operatorname{sion}\left(1 \times 10^{7} \mathrm{spores} / \mathrm{mL}\right)$ to $15 \mathrm{~g}$ dried grape marc. The substrate was supplemented with $2 \%(\mathrm{w} / \mathrm{w})$ wine lees. The flasks were incubated under aseptic conditions at $30^{\circ} \mathrm{C}$ for 5 days.

\subsection{Analysis}

\subsubsection{Chemical analysis}

For estimation of total residual sugars, $1 \mathrm{~g}$ of the samples was suspended in $50 \mathrm{~mL}$ of distilled water. The samples were kept at an ambient temperature for $12 \mathrm{~h}$ for extraction of the sugars. The filtrate was then analyzed for residual sugars in form of glucose and fructose using HPLC (Model 350, Varian, Australia), which was equipped with a Varian Microsorb-MW 100-5 C18 column and a refractive index detector under UV absorbance detection at $254 \mathrm{~nm}$. The column temperature was maintained at $70^{\circ} \mathrm{C}$. The biomass was expressed in terms of total protein content. Total protein was analyzed according to the standard Folin method as described in previous studies (Jin et al., 2002; Zhang et al., 2008). The in vivo digestibility of the grape marc was determined by two stage methods according to Palić and Leeuw (2009). Briefly, in the first, $0.5 \mathrm{~g}$ of dried sample is incubated anaerobically with rumen liquor inoculum in a buffered solution for $48 \mathrm{~h}$ at $38^{\circ} \mathrm{C}$ in the dark. The second stage involves digestion with pepsin- $\mathrm{HCl}$ for $48 \mathrm{~h}$ at $38^{\circ} \mathrm{C}$. The digestibility is calculated as the difference between the organic matter in the original sample and in the residue.

\subsubsection{Data analysis}

All sampling and analysis were conducted in triplicates. All analytical data were calculated from the average values of the triplicates. The results presented in the tables and figures were provided with the deviation of $95 \%$ confidence interval. Standard deviation for each measurement is shown in the relevant figures and tables.

\section{Results and discussion}

\subsection{Selection criteria and procedures}

The protein-enriched grape marc, as the target product of the SSF process, must fulfill certain requirements as an alternative feedstock (Botella et al., 2005; Sanchez et al., 2002). The bioconversion product using fungi must have a high protein content and digestibility, and is safe for human or animal consumption. The screening and selection of the fungal species were conducted in a series of laboratory bench tests. The main criteria for strain selection include biochemical accessibility to use grape marc as a carbon source, growth requirement and rate, and final usability of the fungal biomass. Importantly, these fungi should meet the GRFS status (Joshi and Sandhu, 1996). The screening of suitable fungal species and strains were determined by evaluation of the fermentation results of protein content, digestibility and residual sugar consumption. The protein content gives back the nutritional value for the animal feed, while the digestibility indicates how the carbohydrate based feedstock can be better utilized by the consuming animals. The digestibility is an important parameter to determine overall quality of feedstock. In consideration of the selection criteria and chemical composition of the winery residuals, the fungi must

1) Have a high protein content and be safe for human and animal consumption,

2) Have a broad substrate specificity for grape marc utilization,

3) Have a high microbial conversion efficiency of winery residuals for animal feed,

4) Have high growth rates and should be adaptable for use in a large scale SSF process.

The screening and selection of suitable fungal species and strains were carried out in four stages: (i) screening of candidates, (ii) primary genus selection, (iii) species and strain selection, and (iv) cultivation conditions, as outlined in Fig. 1. The initial screening of the fungus candidates and selection of primary genus were investigated through the literature study and database analysis. During the primary genus selection, the suitable candidates were tested by primarily assessing the biomass growth, carbon source accessibility, and enzyme generation and reducing sugar production of the tested fungi. In the stage of species and strain selection, the suitable species and strains were determined based on their biochemical activities and performance of fungal cell growth, protein enrichment and digestibility in mono-cultivation. We would find out if these tested fungi can be co-cultivated to maximize the protein enrichment and digestibility improvement by the mixed cultures so as to better utilize the carbon and nutrient sources in the winery residuals: grape marc and lees. The present study will only focus on these selection stages as described above.

It is expected that the selected fungi will be tested in a laboratory SSF bioreactor system, which is equipped with on-line monitoring and control units for $\mathrm{pH}$, temperature, dissolved oxygen and water content. The investigations of laboratory SSF system will be conducted to determine operation conditions and fungal growth requirements to maximize the bioconversion performances for improving protein contents and digestibility of the fermented grape marc. Information of 


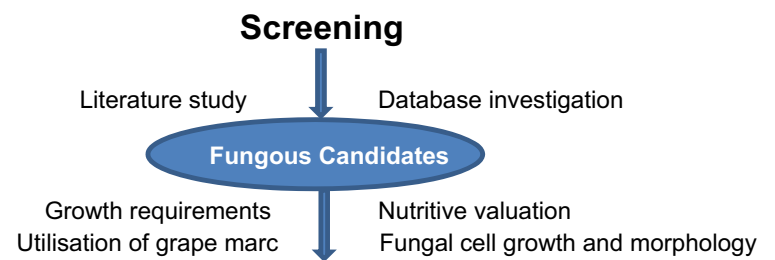

Primary Genus Selection

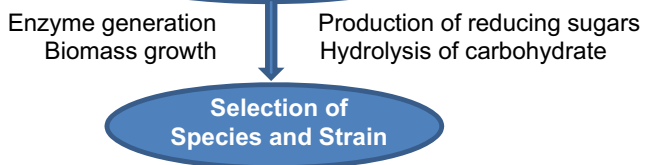

Protein enrichment Digestibility improvement

Desing and Operation of

Laboratory SSF system

Growth requirements

Chemical and nutrients

Reactor configuration and

Operation conditions

\section{Industrial Microbial Fungi}

Fig. 1 - Biotech-systematic strategy of screening and selection of microbial fungi for bioconversion of grape marc to protein-rich animal feed.

nutrient analysis of the fungus-fermented grape marc against standards for animal feed can be important for the commercialization of this bioconversion technology and its product protein enriched feed. Finally, the most suitable fungal strains can be determined as industrial microorganisms.

\subsection{Sugar generation and consumption}

The residual sugars were measured as an indicator of enzymatic and metabolic abilities of the tested fungi using grape marc in the SSF process. It is unlikely to determine the kinetic profiles of the reducing sugar generation and consumption during the SSF system, as the sugars can be consumed simultaneously by the fungal cell growth, enzyme generation, and metabolic production. The residual sugars can be generated by the biochemical reactions induced by the fungal cell growth, while being consumed by the metabolic reactions during the course of fermentation (Karpe et al., 2015a). Thus, the overall residual sugars measured from the SSF tests were the difference between the generation and consumption of the total sugars. To determine the profiles of the total residual sugars accumulated during the course of SSF, the fermented grape marc was sampled and tested against total residual sugars.

We conducted a series of bench tests to analyze the residual sugar profiles during the course of SSF using fungi. It is notable that all fungal species and strains showed more or less similar reducing sugar profiles: consumption phase, accumulation phase, reduction phase and stable low phase during the 7 days fermentation, as shown in Fig. 2a. Fig. 2a presents the profiles of residual sugar generation and consumption of $A$. oryzae RIB 40 during 7 day SSF using RGM and WGM. There is a clear reduction profile of reducing sugars for WGM from $6 \mathrm{~g} / \mathrm{L}$ to $0.7 \mathrm{~g} / \mathrm{L}$ within 2 days fermentation and for RGM from $2 \mathrm{~g} / \mathrm{L}$ to $0.4 \mathrm{~g} / \mathrm{L}$ in 1 day. In the early stage of the SSF, free sugars in the grape marc were consumed for the fungal cell growth, resulting in reducing sugar concentrations to $0.5 \mathrm{~g} / \mathrm{L}$ and $2.1 \mathrm{~g} / \mathrm{L}$ in RGM and WGM, respectively, after $24 \mathrm{~h}$. After 2 days of fermentation, the sugar concentration in WGM was further decreased
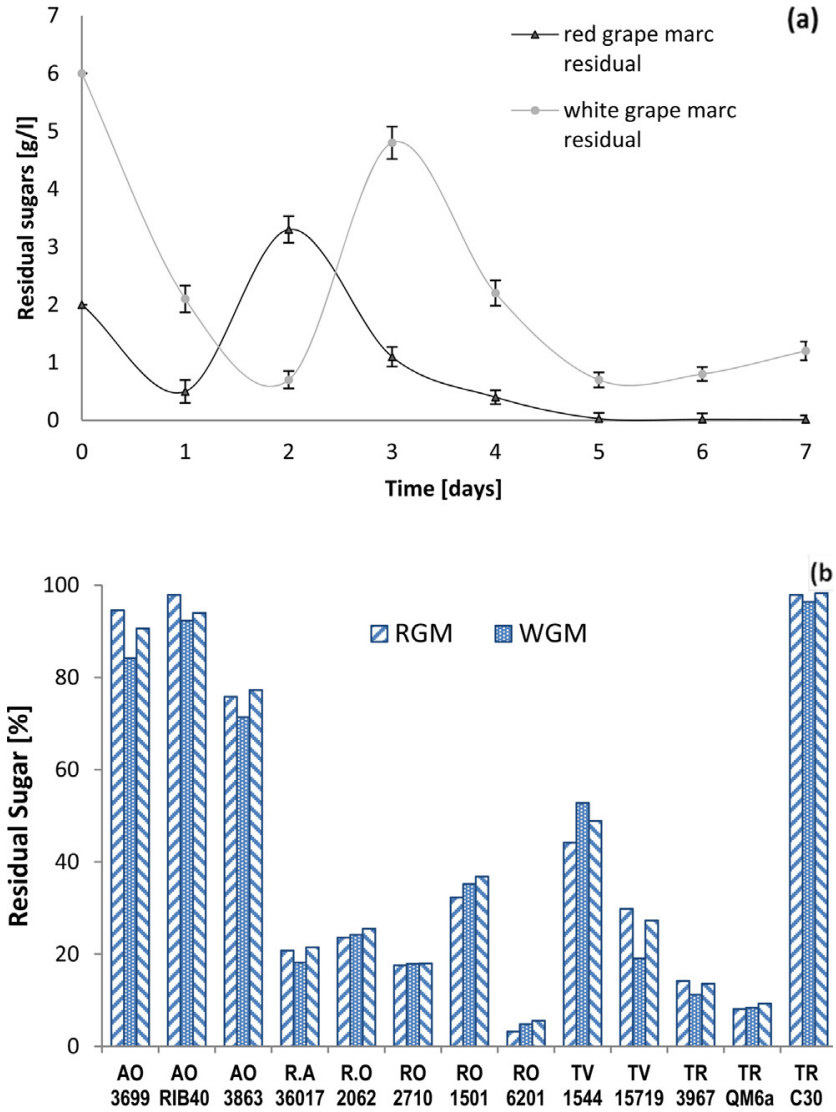

Fig. 2 - (a) Residual sugar profiles in SSF of red and white grape marc using $A$. oryzae RIB 40 , and (b) residual sugar consumption ability of fungi using grape marc (fermentation conditions: temperature $30^{\circ} \mathrm{C}$, water content $65 \%$ and incubation time 7 days) (residual sugars: $S D \pm 0$. 26).

to $0.7 \mathrm{~g} / \mathrm{L}$. It was interesting to note the sugar concentration reached a peak of $3.3 \mathrm{~g} / \mathrm{L}$ in RGM in 2 days and $4.8 \mathrm{~g} / \mathrm{L}$ in WGM in 3 days. This sugar accumulation resulted from the enzymatic saccharification associated with the fungal cell growth. In comparison with the residual sugar profiles in the SSF trials using other fungi (data not shown), we found that these peak levels of the residual sugars corresponded well to those fungal species which showed a high biomass growth, such as $A$. oryzae DAR 3699, A. oryzae RIB 40 and T. reesei RUT C30, whereas the SSF using R. oryzae 6201 and T. reesei QM6a showed a very small and/or no peak level of residual sugars. After the peak level was reached, the residual sugar concentration decreased exponentially. In general, residual sugar achieved a higher level in the WGM than these measured in the RGM during the course of fermentation. This can be explained that the WGM provided more residual sugars of $\sim 8 \%$ glucose and $3 \%$ fructose, compared with $\sim 5 \%$ glucose in the RGM. These results indicated that the tested fungi might be able to access glucose and fructose simultaneously.

We examined sugar consumption ability of the tested fungi in a number of SSF tests using RGM, WGM and mixed red and white grape marc (MGM) as fermentation media. Fig. $2 b$ shows that all Aspergillus sp. appeared to have a better carbon source accessibility to use the residual sugars available in the grape marc. A. oryzae DAR 3699 and A. oryzae RIB 40 performed excellent sugar consumption ability to utilize more than $84 \%$ and $95 \%$ of the sugars in WGM and RGM, respectively. T. reesei RUT C30 demonstrated the highest sugar consumption 
of $96-98 \%$ form all grape marc samples, while T. reesei QM6a and 3967 showed very low sugar consumption ability. T. viride 1544 could consume $52.8 \%$ and $44.2 \%$ residual sugars from WGM and RGM, respectively. The tested Rhizopus sp. showed very low ability to consume the residual sugars. Among Rhizopus sp., the best strain was $R$. oryzae 1501 , which was able to consume $32-37 \%$ sugars in the grape marc samples, while $R$. oryzae 6201 demonstrated the lowest ability to use sugars in the grape marc. There was no significant difference in terms of sugar accessibility for each individual strain using grape marc (Fig. 2b). Botella et al. (2005) stated that a low sugar concentration of $0.05 \mathrm{mM}$ was found after $22 \mathrm{~h}$ fermentation using $\mathrm{A}$. awamori and a peak of $0.14 \mathrm{mM}$ was achieved after $24 \mathrm{~h}$. Cauto et al. (2003) reported similar results in sugar consumptions on grape seeds using yeast.

\subsection{Protein enrichment}

The protein content in the fermented grape marc is the most important parameter which determines the overall quality of the product as animal feed. Here, we have designed and conducted a series of tests to evaluate protein enrichment capability of the tested fungi. It is well known that protein contents can be varied, depending on the microorganisms, and their carbon and nutrient accessibility, as well as the cultivation conditions, such as carbon and nutrient sources, water content and pH (Jin et al., 1999b, 2000). Therefore, the protein enrichment of the fungi was determined and compared with their ability to use reducing sugars and to improve digestibility in this study. The experiments were carried out in the flask SSF tests using the RGM, WGM and MGM incubated at $30^{\circ} \mathrm{C}$ for 7 days. We found that a significant protein enrichment of the grape marc occurred in 4-5 days, while there was a slight and/or a little improvement in protein content and digestibility between 5 and 7 day incubation (data no shown). Therefore, we present analysis data from the samples in 5 day fermentation to evaluate the SSF performance of these tested fungi in the following sections.

Fig. 3a presents the protein contents of the fungifermented grape marc. Three A. oryzae sp. showed a comparably high capability of fungal biomass growth and protein enrichment. A. oryzae 3699 and RIB40, and T. reesi C30 demonstrated the highest ability to enrich protein, achieving a protein content of approximate $20 \%$. Rhizopus sp. appeared to be less promising fungi for protein enrichment. It is interesting to note that T. reesi C30 was one of the best strains for protein enrichment, while two T. reesi 3967 and QM6a grew very poorly on the grape marc. Considering the protein enrichment as the aim of the SSF process, T. reesi 3967 and QM6a, R. oryzae 2062, R. oligosporus 2710 , and R. arrhizus 36017 should not be selected for the SSF process. For individual fungus, higher protein content was found in the fungi-cultured WGM. There was no significant difference in protein content between the fermented RGM and MGM.

Fig. $3 \mathrm{~b}$ presents a promising liner regression relationship between the protein content and sugar consumption $\left(R^{2}=0.8372\right)$ in the fermented grape marc. In general, a high sugar consumption rate corresponded to increasing protein content. However, this relationship can be variable. T. reesei RUT C30 and A. oryzae performed a considerably higher protein enrichment associated with a higher sugar consumption rates. It should be noted that this proportional increase in the protein content with the sugar consumption appeared to be less significant for most of Rhizopus and Trichoderma sp. $R$.
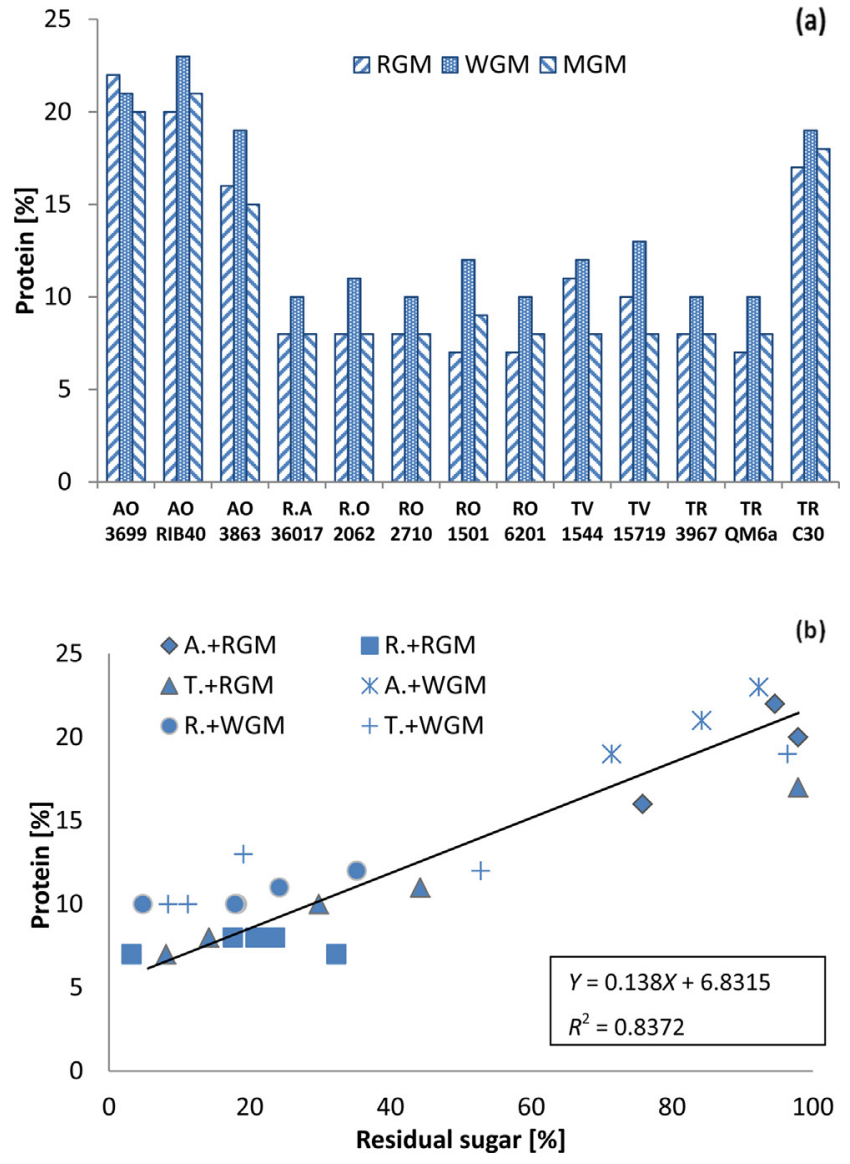

Fig. 3 - (a) Protein contents in the grape marc, and (b) relationship between protein contents and residual sugar consumption in RGM and WGM after 5 day SSF using microbial fungi at $30^{\circ} \mathrm{C}$ with a $65 \%$ water content (protein: $\mathrm{SD} \pm 0.65)$.

oryzae 1501 and T. viride 15719 showed high residual sugar consumption rates of $33 \%$ and $45 \%$, but low protein enhancement by $1-5 \%$. An increase in sugar consumption from $5 \%$ to $35 \%$ by the Rhizopus sp. could lead to a slight increase in protein content in WGR, but a little protein enrichment for RGM. From data shown in Fig. 3a, it can be notable that at least a sugar consumption rate higher than $65 \%$ is needed in the SSF, if one expects to achieve a significant increase in the protein content for the fermented grape marc.

Our results revealed that the bioconversion of the winery residues through the SSF was proved to be a promising approach to enhance protein content in the grape marc. In the present study, four fungi A. oryzae DAR 3699, RIB 40 and 3863, and T. reesei RUT 30 demonstrated excellent bio-accessability in mono-cultivation. These fungi are suitable for protein enrichment. As these fungi have been used in food processing and enzyme production, the fungal biomass produced by these strains can be safe for human and animal consumption (Ghorai et al., 2009; Gummadi and Panda, 2003). Botella et al. (2005) stated that solid grape wastes were competitive with other agricultural wastes when they were used as a substrate in a SSF process. Sanchez et al. (2002) investigated the application of grape pomace for producing animal feed using Pleurotus sp. in SSF. Vendruscolo et al. (2008) used apple pomace as a substrate for protein enrichment through SSF using Rhizopus sp. After 3 days fermentation, protein content reached $11.0 \mathrm{~g}$ per $100 \mathrm{~g}$ dried pomace. They reported that $R$. oryzae showed a potential use of rice bran as a substrate, 

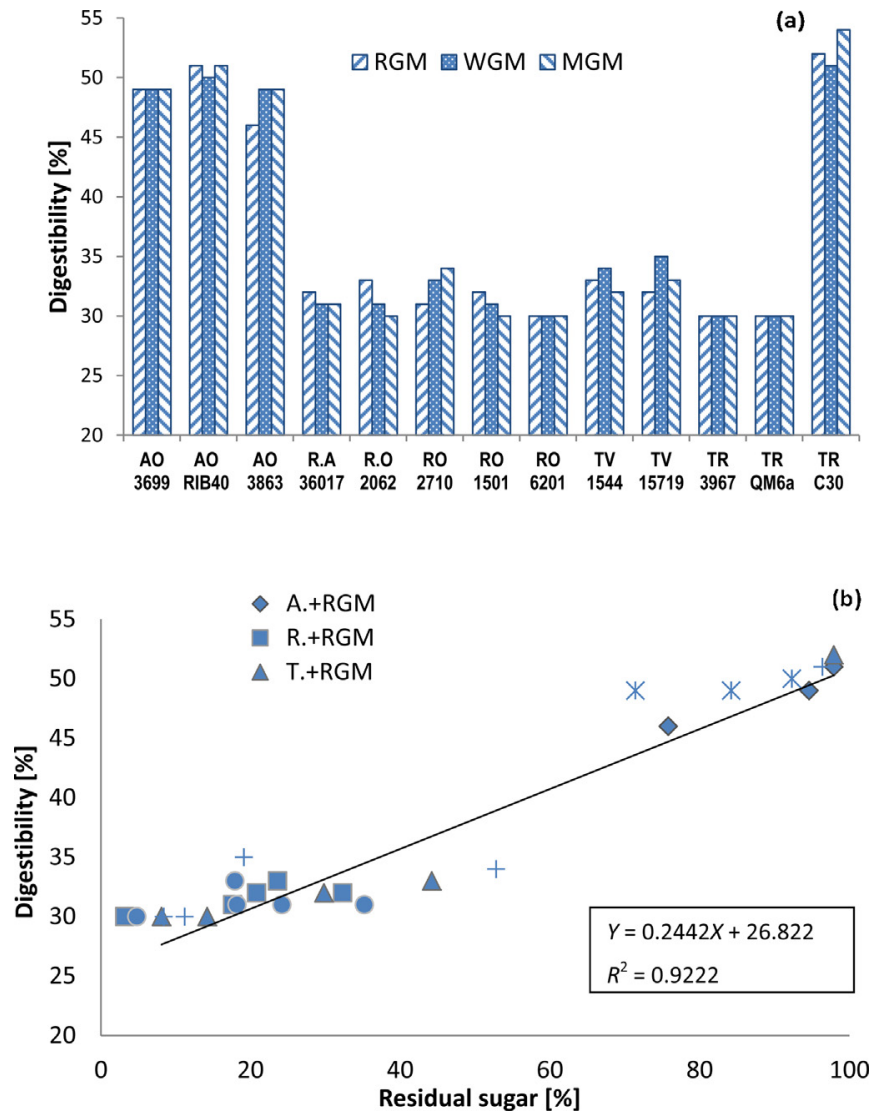

Fig. 4 - (a) Digestibility of the grape marc, and (b) relationship between digestibility and residual sugar consumption in RGM and WGM after 5 day SSF using fungi at $30^{\circ} \mathrm{C}$ with a $65 \%$ water content (digestibility $S D \pm 1.87$ ).

resulting in improving protein concentrations up to $20.4 \mathrm{~g} / 100 \mathrm{~g}$. This protein enrichment was comparably higher than these reported by Pogaku et al. (2009), who used fungous species of A. niger, A. oryzae and T. viride to promote protein contents of rice bran in bench scale SSF systems.

\subsection{Digestibility improvement}

Fig. 4a shows the digestibility improvement in RGM, WGM and MGM after 5 day SSF using the 13 tested fungi. Compared with 25-30\% digestibility of the raw grape marc, we found that only three A. oryzae sp. and T. reesi C30 demonstrated a significant improvement of the digestibility up to $\sim 50 \%$, while a little increase in the digestibility was measured in the trails using the rest nigh Rhizopus and Trichoderma sp. The results showed that there was no significant difference in digestibility of RGM and WGM after the fungi-induced SSF.

Fig. $4 \mathrm{~b}$ displays a well fitted linear regression relationship $\left(R^{2}=0.922\right)$ between the digestibility and sugar consumption meseared in the SSF trails using 13 microbial fungi. This relasionship shows that a high sugar consumption corresponded to a high digestibility in the fermented grape marc. For some fungi, however, this proportional relationship between the digestibility and sugar consumption seems less promising. In the SSF trails using most of the Rhizopus and Trichoderma species, high sugar consumption could lead to a slight increase in the digestibility for either RGM or WGM. Three A. oryzae strains appeared to be very promising fungi for sugar consumption and digestibility improvement in both WGM and

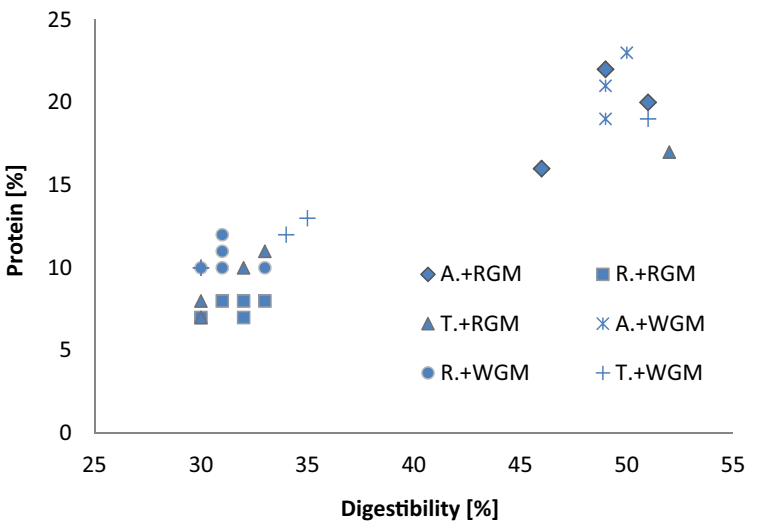

Fig. 5 - Relationship between protein contents and digestibility in RGM and WGM after 5 day SSF using fungi at $30^{\circ} \mathrm{C}$ with a $65 \%$ water content (protein: $\mathrm{SD} \pm 0.58$; digestibility: $\mathrm{SD} \pm 1.38$ ).

RGM, while T. reesei Rut C30 could convert $~ 96 \%$ sugar to enhance digestibility up to $51 \%$.

From the results shown in Figs. 3 and 4, we note that a fungus could generate biomass protein at a high level in the fermented grape marc, corresponding to a high digestibility. Here, we evaluated possible relationship between the protein content and digestibility in the fungi-fermented grape marc, as displayed in Fig. 5. While it seems unlikely to have a clear relationship within the experimental data, we found that the tested fungi could be classified as two groups in terms of their ability to enhance protein content and digestibility. The group one includes three A. oryzae species and T. reesei Rut C30, while second group are the rest of Rhizopus and Trichoderma sp. The highest protein content up to $23 \%$ was achieved by A. oryzae species, leading to the largest increase in digestibility of $~ 50 \%$ in both RGM and WGM. T. reesei Rut C30 could only showed a very high metabolic performance using WGM, resulting in increasing the protein content up to $20 \%$ and digestibility of $54 \%$. The protein content and digestibility could be increased slightly in the SSF tests using Rhizopus sp., and T. viride 1544 and 15719. The fungi in the second group showed low biochemical performances in terms of generation of reducing sugar, and improvement of protein content and digestibility. They will not be considered for further investigations for the bioconversion of grape marc. Our results revealed that the protein content and digestibility of the grape marc can be improved by the fungi-induced SSF process. A few of previous studies reported that the protein contents and digestibility of fruit and vegetable wastes or agricultural by-products can be increased in a SSF process using fungi (Pogaku et al., 2009; Cauto et al., 2003).

\subsection{Nutrient supplementation for protein enrichment}

To investigate if the nutrient supplementation could be beneficial for protein enrichment of grape marc using selected fungi, we employed the commonly used nutrient sources: yeast extract and minerals in the SSF trials. The winery lees were tested as alternative nutrient source in this study. The nutrient tests were carried out by supplementation of $1 \%(\mathrm{w} / \mathrm{w})$ yeast extract, trace elements, and or $1 \%$ yeast extract in combination with trace elements. Further test was conducted with addition of $1.0 \mathrm{~g}$ wine lees to $100 \mathrm{~g}$ of grape marc. A test using RGM as sole substrate was conducted as a reference. These experiments were conducted at $30^{\circ} \mathrm{C}$ using RGM with water 
Table 2 - Protein content $(\%, \mathbf{S D} \pm \mathbf{0 . 6 6})$ in SSF of red grape marc with addition of nutrient sources.

\begin{tabular}{|c|c|c|c|c|c|}
\hline Test strain & No. nutrient supplementation & Yeast extract & Minerals & Yeast extract + minerals & Wine lees \\
\hline A. oryzae DAR 3699 & 22 & 21 & 22 & 26 & 26 \\
\hline A. oryzae RIB 40 & 20 & 22 & 21 & 25 & 26 \\
\hline A. oryzae 3863 & 16 & 18 & 18 & 19 & 21 \\
\hline R. arrhizus 36017 & 8 & 8 & 8 & 11 & 10 \\
\hline R. oryzae 2062 & 8 & 8 & 8 & 10 & 10 \\
\hline R. oligosporus 2710 & 8 & 7 & 8 & 11 & 11 \\
\hline R. oryzae 1501 & 7 & 7 & 7 & 9 & 8 \\
\hline R. oryzae 6201 & 7 & 7 & 7 & 10 & 9 \\
\hline T. viride 1544 & 11 & 10 & 11 & 14 & 12 \\
\hline T. viride 15719 & 10 & 10 & 11 & 13 & 11 \\
\hline T. reesei 3967 & 8 & 9 & 8 & 12 & 9 \\
\hline T. reesei QM6a & 7 & 7 & 7 & 7 & 8 \\
\hline T. reesei RUT C30 & 17 & 19 & 18 & 23 & 24 \\
\hline
\end{tabular}

Table 3 - (a) Protein content $(\%, \mathrm{SD} \pm \mathbf{0 . 6 7 )}$ and (b) digestibility $(\%, S D \pm 1.19)$ of RGM in mono- and co-cultivations of fungi.

\begin{tabular}{|c|c|c|c|c|c|c|c|c|c|c|c|c|c|}
\hline $\begin{array}{l}\text { ᄋ̊ } \\
\text { 유 } \\
\text { 운 }\end{array}$ & 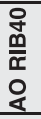 & 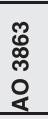 & 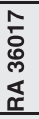 & 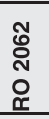 & 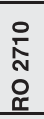 & $\begin{array}{l}\bar{\delta} \\
\stackrel{0}{1} \\
\text { 우 }\end{array}$ & 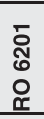 & 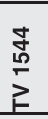 & 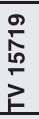 & 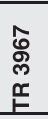 & 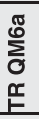 & $\begin{array}{l}\text { ర్ల } \\
\text { 또 } \\
\text {. }\end{array}$ & \\
\hline 26 & 25 & 19 & 11 & 10 & 11 & 9 & 10 & 14 & 13 & 12 & 7 & 23 & \\
\hline \multirow{12}{*}{ (a) } & \multirow[t]{5}{*}{25} & 23 & 22 & 23 & 23 & 23 & 24 & 23 & 22 & 24 & 24 & 24 & AO 3699 \\
\hline & & 22 & 23 & 23 & 22 & 23 & 22 & 23 & 23 & 22 & 23 & 24 & AO 40 \\
\hline & & & 17 & 18 & 17 & 16 & 15 & 18 & 15 & 16 & 17 & 24 & AO 3863 \\
\hline & & & & 11 & 10 & 11 & 9 & 10 & 11 & 11 & 11 & 24 & RA 36017 \\
\hline & & & & & 10 & 10 & 12 & 11 & 10 & 10 & 10 & 24 & RO 2062 \\
\hline & & & & & & 9 & 23 & 13 & 18 & 11 & 10 & 23 & RO 2710 \\
\hline & & & & & & & 10 & 13 & 13 & 10 & 10 & 24 & RO 1501 \\
\hline & & & & & & & & 12 & 12 & 11 & 10 & 24 & RO 6201 \\
\hline & & & & & & & & & 12 & 11 & 14 & 23 & TV 1544 \\
\hline & & & & & & & & & & 11 & 12 & 23 & TV 15719 \\
\hline & & & & & & & & & & & 10 & 24 & TR 3967 \\
\hline & & & & & & & & & & & & 22 & TR QM6a \\
\hline
\end{tabular}

\begin{tabular}{|c|c|c|c|c|c|c|c|c|c|c|c|c|c|}
\hline 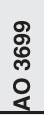 & $\begin{array}{l}\text { 영 } \\
\frac{m}{\bar{x}} \\
\stackrel{0}{\alpha}\end{array}$ & 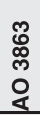 & 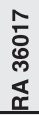 & 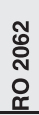 & 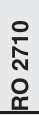 & 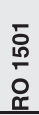 & $\begin{array}{l}\bar{乛} \\
\text { ర్ } \\
\text { O }\end{array}$ & $\frac{\text { J }}{\stackrel{5}{5}}$ & 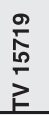 & 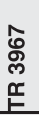 & $\begin{array}{l}\mathbb{E} \\
\sum_{0}^{0} \\
\widetilde{E}\end{array}$ & 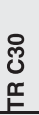 & \\
\hline 49 & 51 & 46 & 32 & 33 & 31 & 32 & 30 & 33 & 32 & 30 & 30 & 52 & \\
\hline \multirow{12}{*}{ (b) } & 49 & 47 & 46 & 46 & 46 & 46 & 48 & 46 & 46 & 46 & 47 & 49 & AO 3699 \\
\hline & & 47 & 46 & 46 & 45 & 47 & 47 & 47 & 46 & 46 & 46 & 46 & AO 40 \\
\hline & & & 32 & 41 & 39 & 41 & 40 & 40 & 39 & 41 & 38 & 47 & AO 3863 \\
\hline & & & & 33 & 32 & 32 & 32 & 32 & 33 & 32 & 32 & 48 & RA 36017 \\
\hline & & & & & 32 & 31 & 31 & 30 & 31 & 30 & 31 & 50 & RO 2062 \\
\hline & & & & & & 30 & 45 & 33 & 33 & 34 & 31 & 48 & RO 2710 \\
\hline & & & & & & & 32 & 34 & 32 & 33 & 30 & 46 & RO 1501 \\
\hline & & & & & & & & 33 & 34 & 33 & 32 & 47 & RO 6201 \\
\hline & & & & & & & & & 31 & 32 & 34 & 47 & TV 1544 \\
\hline & & & & & & & & & & 33 & 31 & 48 & TV 15719 \\
\hline & & & & & & & & & & & 32 & 48 & TR 3967 \\
\hline & & & & & & & & & & & & 47 & TR QM6a \\
\hline
\end{tabular}

content of $\sim 65 \%$. The effect of nutrient supplementation on the protein contents of the fermented RGM can be described in Table 2 .

Our results revealed that the addition of either yeast extract or trace elements could only lead to approximately 1-3\% protein enrichment. A higher protein enrichment can be achieved in the tests using mixed yeast extract and minerals. Providing yeast extra and minerals, the protein contents achieved as much as $26 \%$ by A. oryzae DAR3699 and $25 \%$ by A. oryzae RIB 40 , resulting in enhancing $270 \%$ and $250 \%$ protein content, respectively, compared to the protein content in the raw grape marc.
There was no significant increase in protein content found in the tests using RGM only and/or the nutrient-added RGM with either yeast extract or minerals. T. reesei QM6a appeared to have very low bio-accessability to use RGM even with nutrient supplementation, and, thus is not a suitable fungus for further study. The nutrient supplementation tests showed that Rhizopus sp. is not a promising fungous for protein enrichment of grape marc. Fermentation using yeast extract with minerals could lead to protein enrichment by $\sim 10 \%$ by the Rhizopus sp.

The wine lees were found to be a promising nutrient source for protein enrichment using the tested fungi (Table 2). Approximately $26 \%$ crude protein was achieved in the leesadded grape marc using A. oryzae DAR3699 and RIB40. A. oryzae 3863 and T. reesei RUT C30 showed higher protein concentrations with $21 \%$ and $24 \%$, respectively. All Rhizopus sp. were found less promising for protein enrichment. Among them, $R$. oligosporus 2710 showed the highest protein enrichment up to only $11 \%$, while other Rhizopus sp. showed a minor improvement compared to the $5 \%$ protein content in the raw RGM.

The supplementation of yeast extract in combination with minerals could have a great influence on the fermentation outcome. Researchers found that the supplementation of different nitrogen sources, such as $\mathrm{NH}_{4} \mathrm{H}_{2} \mathrm{PO}_{4}$, urea and yeast extract, showed positive effect on the fermentation performance in the bioconversion processes (Diaz et al., 2012; Hu et al., 2011). Scientists (Botella et al., 2005; Hu et al., 2011) reported that supplementation of nitrogen sources and minerals could be beneficial for the fungal growth in SSF, which agreed with the findings in this study. Diaz et al. (2012) stated that the addition of a nitrogen source and minerals in SSF of grape marc can enhance the enzyme production. Our experimental data revealed that wine lees can be an excellent nutrient source for protein enrichment. The use of wine lees as nutrient supplement for bioprocess appeared to be rarely reported in the literature.

\subsection{Co-cultivation}

The co-cultivation is to employ different microorganisms in a bioprocess. It is expected that the co-cultivation might promote process efficiency, carbon source usability, and productivity of the SSF process. Fungi are able to generate different enzymes for utilizing carbon and nutrient sources (Jin et al., 1999a, 2000). The resulting co-enzymes could enhance biochemical accessability of the fungi, resulting in stimulating cell growth, and increasing production rate and yield. The experiments to identify a co-cultivation strategy 
were carried out through mono-cultivation and 1:1 (number of spores) co-cultivation of the tested fungi using RGM with $2 \%$ wine lees at $30^{\circ} \mathrm{C}$ for 5 days. Table 3 shows the comparable results of protein content and digestibility of RGM under mono- and co-cultivation.

When two fungal species demonstrate supportive enzymatic and metabolic performance, higher protein contents could be achieved by the co-cultures than the mono-cultures. This could be a case in the co-cultivations of $R$. oligosporus 2710 with T. viride 15719 or R. oryzae 6201 (Table 3a). This co-cultivation resulted in increasing protein contents to $18 \%$ and $23 \%$, which corresponded to an increase in the protein contents by $72 \%$ and $171 \%$, respectively, compared to the results achieved by the mono-cultures from $13 \%$ and $11 \%$. Three Aspergillus sp. were able to grow well in their cocultivations. However the total protein enrichment appeared to be less promising. There was a slight change between the mono-cultivation and co-cultivation of Aspergillus sp. R. oryzae 6201 was able to co-grow with Aspergillus sp. and other Rhizopus sp., but did not grow well with the Trichoderma sp. T. reesei 3967 and T. reesei RUT C30 showed a promising co-cultivation ability with Aspergillus sp. and R. oligosporus 2710 and T. viride 1544.

Table $3 \mathrm{~b}$ indicates that the digestibility of RGM could be improved by Rhizopus sp., and Trichoderma sp. if they were co-cultivated with Aspergillus sp. However, this improvement could be contributed by the Aspergillus sp. On the other hand, co-cultivations of Aspergillus sp. with the Rhizopus sp., and or Trichoderma sp. showed a little improvement in digestibility. It is worthwhile to mention that a remarkable digestibility improvement was obtained by the co-cultivation of $R$. oryzae 6201 and 1501, R. oryzae 6201 and R. oligosporus 2710, and T. viride 1544 and $R$. oryzae 1501 . This co-cultivation led to a 10-50\% improvement in digestibility compared to the monoculture SSF. Among them, the co-cultures R. oryzae 6201 and R. oligosporus 2710 showed the highest digestibility improvement by $50 \%$.

The co-cultivation of fungi or other microorganisms is often correlated with improved functionality as compared to the biochemical activities achieved in respective monocultivation. Therefore, mixed cultivation is expected to have advantages over mono-cultivation for higher substrate utilization, productivity, adaptability for the growth environment and contamination resistance (Dwivedi et al., 2011). Meyer and Stahl (2003) revealed that the impact of co-cultivation were strongly dependent on the medium composition, which affected the co-growth of mixed fungi, leading to enhanced carbon source utilization. Yang (1993) conducted a cocultivation using different molds and yeasts, and found that the co-cultivation of mixed molds could enhance protein enrichment, whereas the mixed yeast and mold did not demonstrate supportive biomass growth. Our data showed that co-cultivations of R. oligosporus 2710 with R. oryzae 6201 and T. viride 15719 could significantly improve the protein contents compared to these mono-cultivations. We found that all co-cultivations of the tested fungi demonstrated no negative impact on cell growth.

\section{Conclusion and recommendation}

This paper reports a biotech-systematic approach for the selection of suitable fungi for the bioconversion of grape marc to protein-rich animal feed. The selected fungi can use the grape marc and winery lees as carbon and nutrient sources in a low cost mono- or co-cultivation SSF process. A. oryzae DAR 3699, A. oryzae RIB40 and T. reesei Rut C30 were determined as the best strains based on their performance of biomass growth, and protein enrichment and digestibility improvement. Mono-cultivation of these fungi resulted in a significant increase in protein content by $130 \%$ in WGM and $270 \%$ for RGM. The fungi-cultured SSF could enhance the protein contents up to $26 \%$ and the digestibility over $50 \%$ for the grape marc, making it suitable for protein-rich animal feed. R. oligosporus 2710 with R. oryzae 6201 or T. veridae 15719 showed enhanced metabolic capability by their co-cultivation.

The biotechnological systematic approach developed through this study could have a broad application for selecting industrial microorganisms and assessing bioprocessing performance in mono- and co-cultivations using organic wastes. This study delivers a bioprocessing strategy for the development of an environmentally and economically sustainable integrated "production-treatment biotech-process". This integrated bioprocessing strategy is of today's important challenges for the sustainable production of renewable resources from waste materials. The "green cycle" bioprocess would be beneficial for upgrading the old-fashioned waste treatment and recovery technologies for the cleaner production strategy in industries. To further develop an industrial bioconversion process using these selected fungi, it is necessary to have further detailed studies on metabolic and enzymatic reactions, analysis of metabolites, nutrients (i.e. amino acids), protein assays for proteomic profile, and optimization of growth condition for maximizing protein contents and digestibility. A pilot plant investigation for reactor configuration and operation conditions, and SSF process optimization is necessary. Life cycle analysis of the SSF process should be carried out in association with the pilot plant study. Information of nutrient analysis of the fungus-fermented grape marc against standards for animal feed can be important for the commercialization of this bioconversion technology and its product - protein enriched feed. Finally, the most suitable fungal strains can be determined as industrial microorganisms.

\section{Acknowledgements}

This study was supported by the BioNanotechnology Laboratory for Water and Energy at The University of Adelaide, Australia. Grape marc and wine lees were provided by the Richmond Grove Winery and Orland Wines in South Australia.

\section{References}

Botella, C., de Ory, I., Webb, C., Cantero, D., Blandino, A., 2005. Hydrolytic enzyme production by Aspergillus awamori on grape pomace. Biochem. Eng. J. 26, 100-106.

Cauto, S.R., Rodriguez, R., Gallego, P.P., Sanroman, A., 2003. Biodegradation of grape cluster stems and ligninolytic enzyme production by phaerochaete chrysosporium during semi-solid-state cultivation. Acta Biotechnol. 23, 65-74.

Diaz, A.B., de Ory, I., Caro, I., Blandino, A., 2012. Enhance hydrolytic enzymes production by Aspergillus awamori on supplemented grape pomace. Food Bioprod. Process. 90, 72-78.

Dwivedi, P., Vivekanand, V., Pareek, N., Sharma, A., Singh, R.P., 2011. Co-cultivation of mutant Penicillium oxalicum SAUE-3.510 and Pleurotus ostreatus for biosynthesis of xylanase and laccase under solid-state fermentation. New Biotechnol. 28, 616-626.

Gelinas, P., Barrete, J., 2007. Protein enrichment of potato processing waste through yeast fermentation. Bioresour. Technol. 98, 1138-1143. 
Ghorai, S., Banik, S.P., Verma, D., Chowdhury, S., Mukherjee, S., Khowala, S., 2009. Fungal biotechnology in food and feed processing. Food Res. Int. 102, 128-132.

Gummadi, S., Panda, T., 2003. Purification and biochemical properties of microbial pectinases: a review. Process Biochem. 38, 987-996.

Hu, C.C., Liu, L.Y., Yang, S.S., 2011. Protein enrichment, cellulose production and in-vitro digestion of pangolagrass with SSF. J. Microbiol. Immunol. Infect. 45, 7-14.

Jin, B., Yan, X., Yu, Q., van Leeuwen, J., 2002. A comprehensive pilot plant system for fungal biomass protein production and wastewater reclamation. Adv. Environ. Res. 6, 179-189.

Jin, B., Yu, Q., van Leeuwen, J., 2001. A bioprocessing mode for fungal biomass protein production and wastewater treatment using external air-lift bioreactor. J. Chem. Technol. Biotechnol. 76, 1041-1048.

Jin, B., Yu, Q., Yan, X., van Leeuwen, J., 2000. Characterization and improvement of oxygen transfer in pilot plant air-lift bioreactor for biomass production from wastewater. World J. Appl. Microbiol. Biotechnol. 17, 265-272.

Jin, B., van Leeuwen, J., Patel, B., Doelle, H.W., Yu, Q., 1999a. Production of fungal protein and glucoamylase by Rhizopus oligosporus from starch processing wastewater. Process Biochem. 34, 59-65.

Jin, B., van Leeuwen, J., Yu, Q., Patel, B., 1999b. Screening and selection of microfungi for microbial biomass protein production and water reclamation from starch processing wastewater. J. Chem. Technol. Biotechnol. 74, 106-110.

Joshi, V.K., Sandhu, D.K., 1996. Preparation and evaluation of animal feed using solid state fermentation of apple pomace. Bioresour. Technol. 56, 251-255.

Karpe, A.V., Beale, D.J., Godhani, N.B., Morrison, P.D., Harding, I.H., Palombo, E.A., 2015a. Untargeted metabolic profiling of winery-derived biomass waste degradation by Penicillium chrysogenum. J. Agric. Food Chem. 63 (49), 10696-10704.
Karpe, A.V., Beale, D.J., Harding, I.H., Palombo, E.A., $2015 b$. Optimization of degradation of winery-derived biomass waste by Ascomycetes. J. Chem. Eng. Technol. 90, 1793-1801.

Meyer, V., Stahl, U., 2003. The influence of co-cultivation on expression of the antifungal protein in Aspergillus giganteus. J. Basic Microbiol. 43 (1), 68-74.

Palić, D.V., Leeuw, K., 2009. Comparison of three in vitro methods for determining and predicting the organic matter digestibility of complete diets for ruminants. APTEFF 40, 1-220.

Petre, M., Zarnea, G., Adrian, P., Ghearghiu, E., 1999.

Biodegradation and bioconversion of cellulose wastes using bacterial and fungal cells immobilized in radiopolymerized hydrogels. Resour. Conserv. Recycl. 27, 309-332.

Pogaku, R., Rudravaram, R., Chandel, A.K., Linga, V.R., Yim, Z.H., 2009. The effect of de-oiled rice bran for single cell protein production using fungal cultures under solid state fermentation. Int. J. Food Eng. 5, 1-12.

Sanchez, A., Ysunza, F., Beltran-Garcia, M., Esqueda, M., 2002. Biodegradation of viticulture wastes by Pleurotus: a source of microbial and human food and its potential use in animal feeding. J. Agric. Food Chem. 50, 2537-2542.

Sankaran, S., Khanal, S.K., Jasti, N., Jin, B., Pometto, A.L., van Leeuwen, J., 2010. Use of filamentous fungi for wastewater treatment and production of high value fungal byproducts: a review. Crit. Rev. Environ. Sci. Technol. 40 (5), 400-449.

Vendruscolo, F., Albuquerque, P.M., Streit, F., 2008. Apple pomace: a versatile substrate for biotechnological applications. Crit. Rev. Biotechnol. 28, 1-12.

Yang, S.S., 1993. Protein enrichment of sweet potato residue with co-culture of amylolytic fungi by solid-state fermentation. Biotechnol. Adv. 11, 495-503.

Zhang, Z.Y., Jin, B., Bai, Z.H., Wang, X.Y., 2008. Production of fungal biomass protein using microfungi from winery wastewater treatment. Bioresour. Technol. 99, 3871-3876. 